\title{
Atmospheric transmission coefficient modelling in the infrared for thermovision measurements
}

\author{
W. Minkina and D. Klecha \\ The Faculty of Electrical Engineering, Częstochowa University of Technology, Częstochowa, 42-200, Poland \\ Correspondence to: W. Minkina (minkina@el.pcz.czest.pl)
}

Received: 6 August 2015 - Revised: 19 November 2015 - Accepted: 4 January 2016 - Published: 20 January 2016

\begin{abstract}
The aim of this paper is to discuss different models that describe atmospheric transmission in the infrared. They were compared in order to choose the most appropriate one for certain atmospheric conditions. Universal models and different inaccuracies connected with them were analysed in this paper. It is well known that all these models are different, but the aim of this paper is calculate how big the differences are between the characteristics of atmospheric transmission as a function of the distance. There have been models analysed from the literature, and these are used in infrared cameras. Correctly measured atmospheric transmission allows the correct temperature of an object to be determined, which is very vast problem that is discussed in paper.
\end{abstract}

\section{Introduction}

The atmospheric transmission in the infrared (IR) is an important parameter in thermovision measurements. This is due to the fact that, when the temperature of an object is measured, the atmosphere which is between the thermal imaging camera and the object attenuates infrared radiation emitted by the object. Additionally, it has been observed, even in laboratory conditions, that at distance of $1-10 \mathrm{~m}$, the atmospheric absorption, caused by water vapour and carbon dioxide, is noticeable. The most important role in absorption of the infrared radiation for the wavelength $\lambda=4.3 \mu \mathrm{m}$ is played by carbon dioxide, present in the exhaled air (Rudowski, 1978). It was stated, for example, that after $3 \mathrm{~h}$ of two persons being in a closed room, about $40 \mathrm{~cm}^{3}$ in volume, the concentration of $\mathrm{CO}_{2}$ was such that, at distance $d=0.8 \mathrm{~m}, 70 \%$ of radiation of the wavelength $\lambda=4.3 \mu \mathrm{m}$ was absorbed by the air (Rudowski, 1978).

Correctly measured atmospheric transmission allows the correct temperature of an object to be determined. In the case of there being no precise model describing the atmospheric transmission in the thermal imager microcontroller (Minkina and Dudzik, 2006, 2009; Minkina et al., 2010), the obtained temperature of the object would be wrong, lower or higher. The atmospheric attenuation depends strongly on the wavelength. For some wavelengths there is very low attenuation over distance of several kilometres, whereas for other wave- lengths the radiation is attenuated to close to nothing over a few metres. The attenuation in the atmosphere does not allow the total original radiation from the object to reach the camera. If no correction for the attenuation is applied, then the measured apparent temperature will be lower and lower with increased distance. The influence of distance on the temperature measurement for the short-wave (SW) and long-wave (LW) camera, without taking into account correction of the impact of the atmosphere on the measurement, can be clearly seen in Fig. 1.

The paper compares different methods of calculating the atmospheric transmission coefficient in the infrared which can be found in practice and in the literature. When a model is chosen, such factors as accuracy and the time needed to do the measurements should be taken into consideration. Greater accuracy means a longer time needed for the calculations. In fact, that subject of research about the atmospheric transmission has a wide range, but this paper has some limitations. The paper concentrates only on the atmosphere's impact on the measurement. The effect of the IR radiation emitted by the absorbing atmosphere (Kirchhoff's law) was skipped in this case and will be considered in the subsequent paper. Thermal imaging cameras operate in a particular infrared range, for which the atmospheric transmission coefficient will be different than for the whole band. 


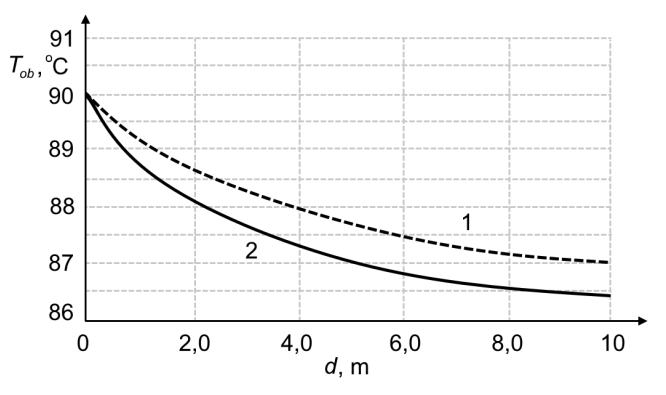

Figure 1. The influence of distance to the temperature measurement for the thermal imaging cameras without taking into account correction of the impact of the atmosphere on the measurement: (1) LW, 8-12 $\mu \mathrm{m}$ and (2) SW, 2-5 $\mu \mathrm{m}$ - an example (IR-Book, 2000).

\section{Thermal imaging cameras AGEMA $880 \mathrm{LW}$ and AGEMA 470 Pro SW}

Depending on a thermovision camera model, there are several different models of the atmosphere transmittance, such as FASCODE, MODTRAN and SENTRAN (Anderson et al., 1995; Rothman et al., 2005; Vollmer and Möllmann, 2010, Pręgowski and Świderski, 1996; Pręgowski, 2001). For example, in the AGEMA 470 Pro SW and AGEMA $880 \mathrm{LW}$ systems, the manufacturer employs the following simplified equation that describes the atmospheric transmission in the infrared, using the LOWTRAN model:

$P_{\mathrm{atm}}(d)=\exp \left[-\alpha \cdot\left(\sqrt{d}-\sqrt{d_{\mathrm{cal}}}\right)-\beta \cdot\left(d-d_{\mathrm{cal}}\right)\right]$,

where $P_{\text {atm }}$ is atmospheric transmission; $d$ is camera-object distance (in $\mathrm{m}$ ); $d_{\text {cal }}$ is camera-object distance (in $\mathrm{m}$ ) (in calibration process - the value of $1 \mathrm{~m}$ ); and $\alpha$ and $\beta$ are coefficients specified for normal conditions: atmospheric temperature $T_{\text {atm }}=15^{\circ} \mathrm{C}$, relative humidity $\omega \%=50 \%$. For SW bands, $\alpha=0.393$ and $\beta=0.00049$; for LW bands, $\alpha=0.008$ and $\beta=0$.

The given values are determined in normal conditions of atmospheric temperature $T_{\mathrm{atm}}=15^{\circ} \mathrm{C}$ and relative humidity $\omega \%=50 \%$. Under different conditions, the atmospheric transmittance model will be different. The value of coefficient $P_{\text {atm }}$ vs. distance $d$ between the camera and the object is shown in Fig. 2a for a LW camera (1) and a SW camera (2). These relationships were obtained from numerical computations using Eq. (1). One can see that the atmosphere has greater transmittance within the LW infrared band. Very similar results are presented in Narasimhan and Nayar (2002) and Orlove (1982).

\section{ThermaCAM PM 595 LW}

The transmittance model defined by FLIR for the ThermaCAM PM 595 camera is a function of three variables: atmospheric relative humidity $\omega \%$, camera-to-object distance
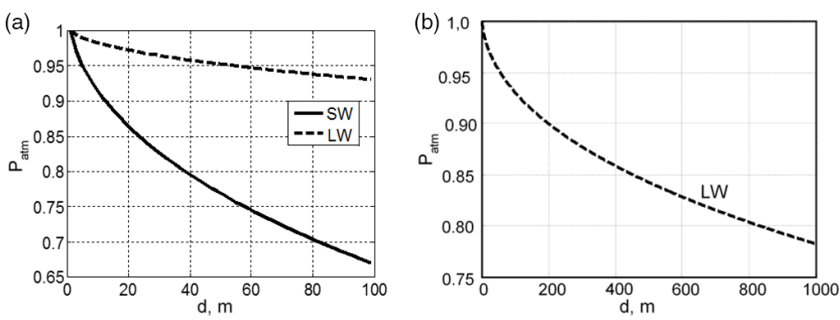

Figure 2. Characteristics of atmospheric transmission coefficient $P_{\mathrm{atm}}=f(d)$ for AGEMA 880 as a function of the camera-object distance $d$ for LOWTRAN model (Eq. 1 ) and $T_{\text {atm }}=15^{\circ} \mathrm{C}, \omega \%=$ $50 \%$, for (a) $d<100 \mathrm{~m}$ (LW and SW camera) and (b) $d<1000 \mathrm{~m}$ (LW camera for further comparisons).

$d$ and atmospheric temperature $T_{\text {atm }}$ (Toolkit IC2, 2001):

$P_{\mathrm{atm}}=\mathrm{f}\left(\omega \%, d, T_{\mathrm{atm}}\right)$.

This model was applied to error and uncertainty analysis in the monograph (Minkina and Dudzik, 2009). It is actually very complex. It includes, among others, nine coefficients adjusted empirically. The explicit form of function (Eq. 2) is copyrighted and reserved by the camera manufacturer (Toolkit IC2, 2001). It was made available to the authors only for research purposes, so we may not publish it here. We are allowed to present the characteristics of the atmospheric transmittance $P_{\text {atm }}$ as a function of camera-to-object distance $d$. The results, shown in Fig. 3, were obtained by numerical simulations using the full form of Eq. (2).

It should be emphasized that the model described with Eq. (2) concerns most of the infrared cameras produced by the AGEMA company (e.g. 900 series) and FLIR company (e.g. ThermaCAM PM 595 LW).

Finally, the thermovision camera measurement model is defined as a function of five variables (Minkina and Klecha, 2015):

$T_{\mathrm{ob}}=\mathrm{f}\left(\varepsilon_{\mathrm{ob}}, T_{\mathrm{atm}}, T_{\mathrm{o}}, \omega \%, d\right)$,

where $\varepsilon_{\mathrm{ob}}$ is emissivity of the object, $T_{\mathrm{o}}$ is ambient temperature, and $T_{\mathrm{atm}}$ is atmospheric temperature, the same as in Eq. (2).

We want to emphasize that the model derived above is a simplified model. In reality, the camera detector receives radiation not only from the object but also from other sources. The simplification can be explained looking at Fig. 4.

The signal proportional to the ambient radiation intensity and dependent on ambient temperature $T_{\mathrm{O}}$ is in reality an average response to radiation coming from clouds of temperature $T_{\mathrm{cl}}$, buildings of temperature $T_{\mathrm{b}}$, ground of temperature $T_{\mathrm{gr}}$ and from the atmosphere of temperature $T_{\mathrm{atm}}$. All these temperatures differ a little from each other (Orlove, 1982; DeWitt, 1983; Saunders, 1999).

Equations (2) and (3) for calculating atmospheric transmission coefficient $P_{\text {atm }}$ include all parameters affecting 

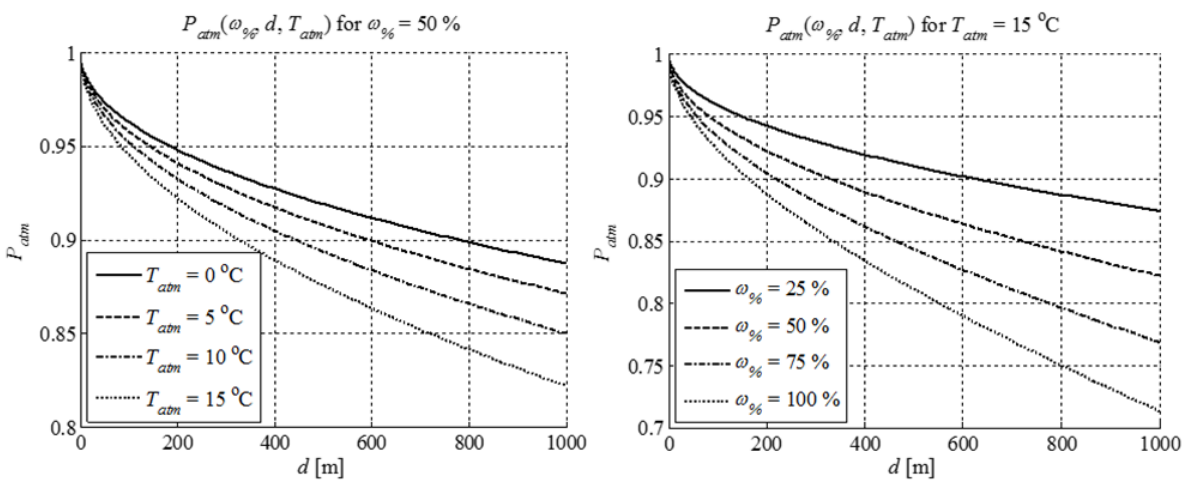

Figure 3. Simulation characteristics of the atmospheric transmittance $P_{\mathrm{atm}}=f(d)$ vs. camera-to-object distance $d$ for full form of model (Eq. 2) as a function of the (a) temperature of the atmosphere $T_{\mathrm{atm}}, \omega \%=50 \%$, and (b) relative humidity of the atmosphere $\omega \%, T_{\mathrm{atm}}=$ $15^{\circ} \mathrm{C}$.

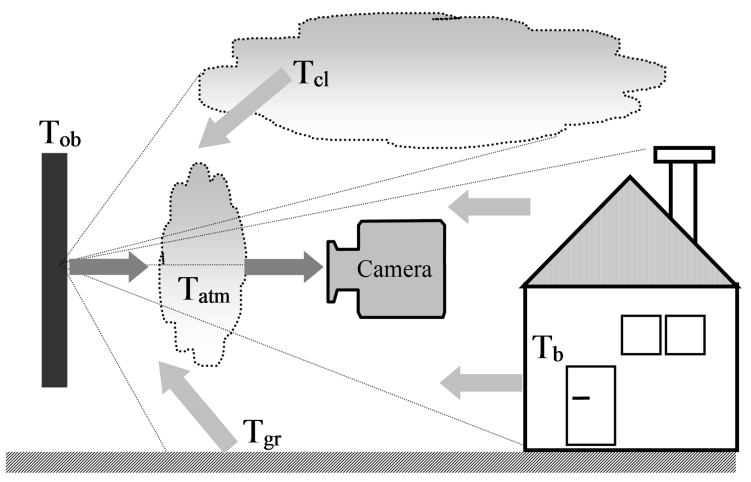

Figure 4. Explanation of simplifications assumed in the thermovision camera measurement model $(2,3)$; ambient temperature $T_{\mathrm{O}}$ is an average of temperatures of clouds $T_{\mathrm{cl}}$, atmosphere $T_{\mathrm{atm}}$, ground $T_{\mathrm{gr}}$ and e.g. buildings $T_{\mathrm{b}}$ (Minkina and Dudzik, 2009).

thermal measurement; therefore they are universal equations which can be used in practice by FLIR (Toolkit IC2, 2001).

\section{Passman-Larmore tables}

Using experimental studies conducted by Passman and Larmore (1956), the characteristics of the transmission coefficient can be calculated precisely. Gas composition influences the results of measurements carried out using a thermovision camera. In this case, the most important are the absorbance coefficients: vapour absorbance $\left(P_{\mathrm{H}_{2} \mathrm{O}}\right)$ and carbon dioxide absorbance $\left(P_{\mathrm{CO}_{2}}\right)$. According to Eq. (4) we have (Gaussorgues, 1994)

$$
P_{\text {atm }} \cong P_{\mathrm{H}_{2} \mathrm{O}} \cdot P_{\mathrm{CO}_{2}} \text {. }
$$

The vapour absorbance depends on the number of absorbing molecules, i.e. on the partial pressure of water vapour, and the distance $d$ travelled by radiation in the absorbing medium. It is usually defined as height $h$ of the cylinder with diameter $D$. The volume of cylinder is equal to the volume of

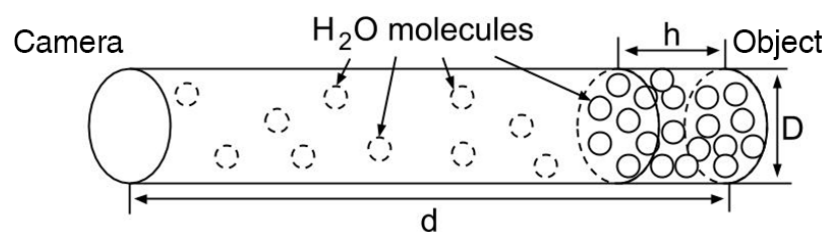

Figure 5. The figure shows the cylinder with height $d$ and diameter $D$; it includes amount of water vapour, and it is at the distance of measurement using the thermovision camera (Gaussorgues, 1994).

liquid obtained by condensation of water vapour contained in the cylinder with diameter $D$ and height $d$, reflecting the atmosphere which is at the distance $d$, where the thermovision camera measurement is taken for $d=1 \mathrm{~km}$. It is also shown in Fig. 5. Taking into consideration the equations described above, the following equation can be used:

$h=\frac{4 \cdot V_{\mathrm{H}_{2} \mathrm{O}}}{\pi D^{2}}$,

where $V_{\mathrm{H}_{2} \mathrm{O}}$ is the volume of liquid obtained by condensation of water vapour in the absorbing medium $\left(\mathrm{m}^{3}\right)$ and $D$ is the diameter of the cylinder representing the absorbing medium $\left(\mathrm{m}^{2}\right)$.

Vapour absorbance $P_{\mathrm{H}_{2} \mathrm{O}}$ depends on molecular processes which are responsible for a selective absorption spectrum. $P_{\mathrm{H}_{2} \mathrm{O}}$ also depends on temperature and total pressure of the gas mixture which regulates the width of absorbing lines as a result of molecular collisions and the Doppler effect.

There is a relationship between the height of the cylinder with water $h$ (Eq. 2), temperature $T_{\text {atm }}$ and relative humidity $\omega \%$. An approximation of a function was obtained using of the Newton method $h(d)$ described in Gaussorgues (1994) and its dependency on relative humidity and distance was taken into consideration according to Eq. (3). See the function in Fig. 6. 


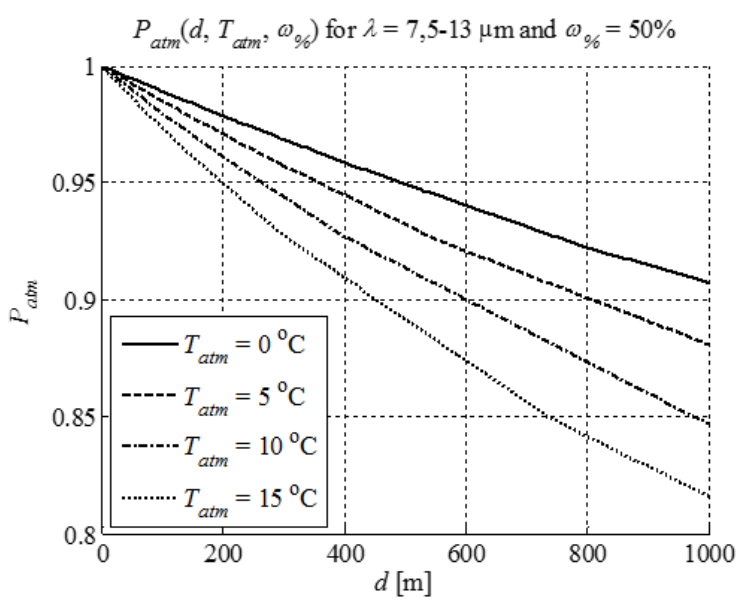

Figure 6. Characteristics of coefficient $h, \mathrm{~m} \mathrm{~km}^{-1}$ for $d=1 \mathrm{~km}$, according to the Eq. (6).

Table 1. A part of the Passman-Larmore table for vapour absorbance $P_{\mathrm{H}_{2} \mathrm{O}}$ (Gaussorgues, 1994; Passman and Larmore, 1956).

\begin{tabular}{rrrrrrrr}
\hline \multirow{2}{*}{$\lambda, \mu \mathrm{m}$} & \multicolumn{7}{c}{$P_{\mathrm{H}_{2} \mathrm{O}}$} \\
\cline { 2 - 8 } & $0 . \mathrm{mm} \mathrm{km}^{-1}$ \\
\cline { 2 - 8 } & 0.2 & 0.5 & 1 & 2 & 5 & 10 & 20 \\
\hline 7.5 & 0.947 & 0.874 & 0.762 & 0.582 & 0.258 & 0.066 & 0 \\
8.0 & 0.990 & 0.975 & 0.951 & 0.904 & 0.777 & 0.603 & 0.365 \\
8.5 & 0.994 & 0.986 & 0.972 & 0.944 & 0.866 & 0.750 & 0.562 \\
9.0 & 0.997 & 0.992 & 0.984 & 0.968 & 0.921 & 0.848 & 0.719 \\
9.5 & 0.997 & 0.993 & 0.987 & 0.973 & 0.934 & 0.873 & 0.762 \\
10.0 & 0.998 & 0.994 & 0.988 & 0.975 & 0.940 & 0.883 & 0.780 \\
10.5 & 0.998 & 0.994 & 0.988 & 0.976 & 0.941 & 0.886 & 0.784 \\
11.0 & 0.998 & 0.994 & 0.988 & 0.975 & 0.940 & 0.883 & 0.779 \\
11.5 & 0.997 & 0.993 & 0.986 & 0.972 & 0.932 & 0.868 & 0.753 \\
12.0 & 0.997 & 0.993 & 0.987 & 0.974 & 0.937 & 0.878 & 0.770 \\
12.5 & 0.997 & 0.993 & 0.986 & 0.973 & 0.933 & 0.871 & 0.759 \\
13.0 & 0.997 & 0.992 & 0.984 & 0.967 & 0.921 & 0.846 & 0.718 \\
\hline
\end{tabular}

$$
\begin{aligned}
h\left(T_{\mathrm{atm}}, d, \omega \%\right) & =\left(1.6667 \cdot 10^{-4} \cdot T_{\mathrm{atm}}^{3}+10^{-2} \cdot T_{\mathrm{atm}}^{2}\right. \\
& \left.+3.8333 \cdot 10^{-1} \cdot T_{\mathrm{atm}}+5\right) \omega \% \cdot d \cdot 10^{-3},
\end{aligned}
$$

where $h$ is height of the cylinder with water (in $\mathrm{m} \mathrm{km}^{-1}$ ); $T_{\text {atm }}$ is the ambient temperature (in ${ }^{\circ} \mathrm{C}$ ); $\omega \%$ is relative humidity (\%); and $d$ is distance (in $\mathrm{km}$ ).

Taking into account distance $d$, height of the cylinder with water $h$ and wavelength $\lambda$, the appropriate values of $P_{\mathrm{H}_{2} \mathrm{O}}$ and $P_{\mathrm{CO}_{2}}$ can be determined using the Passman-Larmore tables. When these values are placed into Eq. (4), it is possible to calculate the atmospheric transmission coefficient $P_{\text {atm }}$. The appropriate part of Passman-Larmore tables is shown in Tables 1 and 2.
Table 2. A part of the Passman-Larmore table for carbon dioxide absorbance $P_{\mathrm{CO}_{2}}$ (Gaussorgues, 1994; Passman and Larmore, 1956).

\begin{tabular}{rrrrrrrr}
\hline$\lambda, \mu \mathrm{m}$ & \multicolumn{7}{c}{$P_{\mathrm{CO}_{2}}$} \\
\cline { 2 - 8 } & \multicolumn{7}{c}{$d, \mathrm{~km}$} \\
\cline { 2 - 8 } & 0.2 & 0.5 & 1 & 2 & 5 & 10 & 20 \\
\hline 7.5 & 1.000 & 1.000 & 1.000 & 1.000 & 1.000 & 1.000 & 1.000 \\
8.0 & 1.000 & 1.000 & 1.000 & 1.000 & 1.000 & 1.000 & 1.000 \\
8.5 & 1.000 & 1.000 & 1.000 & 1.000 & 1.000 & 1.000 & 1.000 \\
9.0 & 1.000 & 1.000 & 1.000 & 1.000 & 1.000 & 1.000 & 1.000 \\
9.5 & 0.993 & 0.983 & 0.967 & 0.935 & 0.842 & 0.715 & 0.512 \\
10.0 & 1.000 & 1.000 & 0.999 & 0.997 & 0.994 & 0.989 & 0.978 \\
10.5 & 1.000 & 1.000 & 0.999 & 0.998 & 0.998 & 0.995 & 0.991 \\
11.0 & 1.000 & 0.999 & 0.999 & 0.997 & 0.993 & 0.986 & 0.973 \\
11.5 & 0.999 & 0.998 & 0.996 & 0.992 & 0.980 & 0.960 & 0.921 \\
12.0 & 1.000 & 1.000 & 0.999 & 0.999 & 0.997 & 0.993 & 0.986 \\
12.5 & 0.987 & 0.968 & 0.936 & 0.877 & 0.719 & 0.517 & 0.268 \\
13.0 & 0.991 & 0.977 & 0.955 & 0.912 & 0.794 & 0.630 & 0.397
\end{tabular}

\section{Example.}

Calculate the atmospheric transmission coefficient for $\lambda=$ $13 \mu \mathrm{m}, d=500 \mathrm{~m}, \omega \%=50 \%,(\omega=0.5)$ and $T_{\mathrm{atm}}=20^{\circ} \mathrm{C}$.

Using Eq. (3) the result is $h\left(T_{\mathrm{atm}}, d, \omega \%\right)=(1.6667 \times$ $\left.10^{-4} \times 203+10^{-2} \times 202+3.8333 \times 10^{-1} \times 20+5\right) \times 0.5 \times 0.5 \times$ $10^{-3}=4.5 \times 10^{-3} \approx 5 \times 10^{-3}$. When the values are placed in Table 1 and 2, the results are 0.921 and 0.977. Next they are placed into Eq. (4); in this way the value of atmospheric transmission coefficient is calculated, and it is equal approximately to 0.900 .

In order to adapt the results to models described in paragraphs 2 and 3 , the average characteristics for the wavelength $\lambda=7.5-13 \mu \mathrm{m}$ are shown in Fig. 7 .

The tables were obtained on the basis of experimental studies, and that is why the model seems to give the most accurate value of the atmospheric transmission coefficient $P_{\mathrm{atm}}$. Calculating atmospheric transmission coefficient by means of the final value of $P_{\text {atm }}$ is time-consuming.

\section{Approach adopted in the paper of Więcek (2011)}

The paper of Więcek (2011) gives another atmospheric transmission model in the infrared $P_{\text {atm }}$. First, Eq. (7) describing saturation vapour pressure was introduced:

$$
p_{\mathrm{S}}\left(T_{\mathrm{atm}}\right)=\left\{\begin{array}{c}
6.112 \cdot \mathrm{e}^{21.874 \frac{T_{\mathrm{atm}}-273.17}{T_{\mathrm{atm}}-7.66}} \\
\text { for } T_{\text {atm }}<273.15 \mathrm{~K} \\
6.112 \cdot \mathrm{e}^{17.269} \frac{T_{\mathrm{atm}}-273.17}{T_{\mathrm{atm}}-35.86} \\
\text { for } T_{\text {atm }} \geq 273.15 \mathrm{~K}
\end{array},\right.
$$

where $p_{\mathrm{s}}$ is saturation vapour pressure (in $\mathrm{Pa}$ ) and $T_{\mathrm{atm}}$ is temperature of the atmosphere (in K).

Next, the value of the coefficient $\alpha_{\lambda}$ was calculated. It describes the cross section of the vapour molecule 


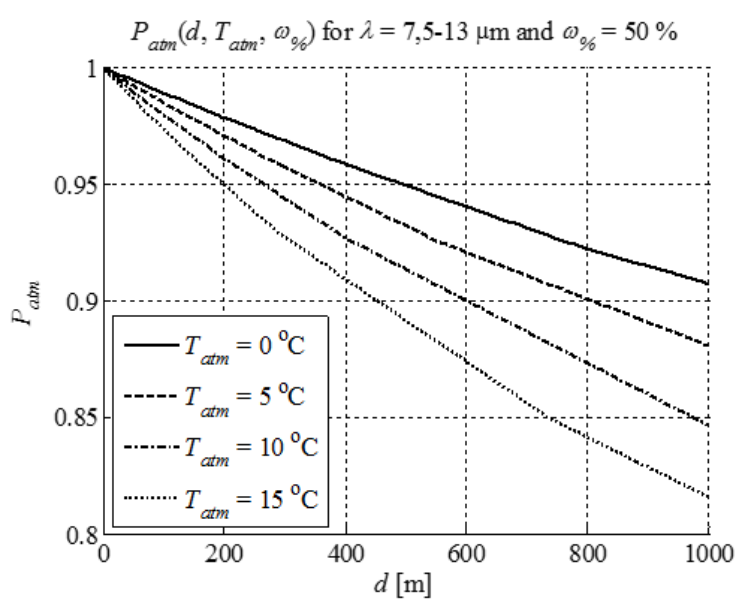

Figure 7. Characteristics of atmospheric transmission coefficient $P_{\mathrm{atm}}=f(d)$ calculated using Passman-Larmore tables.

which depends on the wavelength (Eq. 8). In the paper of Więcek (2011) Eq. (8) describes the correlation resulting from Beer's law and ideal gas law:

$\alpha_{\lambda}=-\frac{k_{\mathrm{B}} \cdot T_{\mathrm{atm}}}{\omega \% \cdot p_{\mathrm{s}} \cdot d} \ln \left(P_{\mathrm{atm}}\right)$,

where $k_{\mathrm{B}}=1.28 \times 10^{-23}$ is the Boltzmann constant $(\mathrm{J} / \mathrm{K})$; $T_{\mathrm{atm}}$ is temperature of the atmosphere (in $\mathrm{K}$ ); $\omega \%$ is relative humidity $(\%) ; p_{\mathrm{s}}$ is saturation vapour pressure (in $\mathrm{Pa}$ ); $d$ is the camera-object distance (in $\mathrm{m}$ ); and $P_{\text {atm }}$ is the value of the atmospheric transmission coefficient resulting from calibration measurements or literature data (e.g. PassmanLarmore tables; see the example above).

Using Eqs. (4) and (5) and assuming constant wavelength $\lambda$, the atmospheric transmission coefficient $P_{\text {atm }}$ can be calculated according to the equation (Więcek, 2011)

$\mathrm{P}_{\mathrm{atm}}\left(d, T_{\mathrm{atm}, \omega \%}\right)=\mathrm{e}^{-\alpha_{\lambda} d \frac{p_{\mathrm{s}} \omega \%}{k_{\mathrm{B}} T_{\mathrm{atm}}}}$.

The calibration value is $P_{\mathrm{atm}}=0.8160$. For the method of calculating this value, see example. It was calculated using Passman-Larmore tables for $d=1000 \mathrm{~m}, \omega \%=50 \%$, $T_{\mathrm{atm}}=15^{\circ} \mathrm{C}$ and $\lambda=7.5-13 \mu \mathrm{m}$. The distance selected in the calculation of the calibration value was chosen experimentally. Figure 8 presents the functions of the coefficient.

Equation (6) gives satisfactory results of $P_{\mathrm{atm}}$, but it is a huge obstacle to set the calibration point properly.

\section{Comparison of the functions}

In order to compare all models describing atmospheric transmission $P_{\text {atm }}$ in the infrared analysed in this paper, the same parameters were applied, e.g. $T_{\mathrm{atm}}=15^{\circ} \mathrm{C}, \omega \%=50 \%$ and $\lambda=7-13.5 \mu \mathrm{m}$. The first two models were defined for LW bands, where the average wavelength was used. To adapt the scope to the Passman-Larmore model, Tables 1 and 2 in the

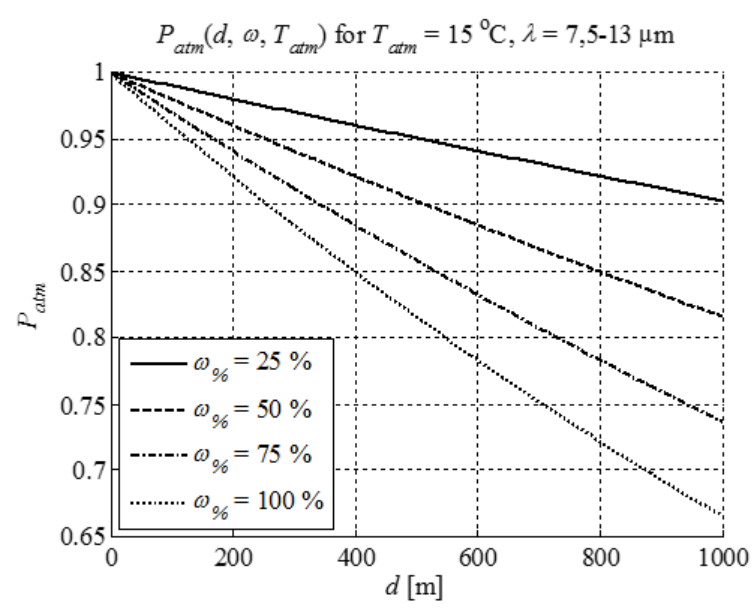

Figure 8. Characteristics of atmospheric transmission coefficient $P_{\text {atm }}=f(d)$ calculated according to the approach given in (Więcek, 2011).

range 7-13.5 $\mu \mathrm{m}$ and the average result were used. For $h$ values which were not in the tables we have carried out linear averaging in relation to the two nearest points. The model (Eq. 6) shown in this paper (Więcek, 2011) depends on the calibration value. The calibration value that was calculated in paragraph 5 and which amounted to 0.8160 was used.

\section{Conclusions}

The atmosphere attenuates infrared radiation of an object whose temperature is measured. In the case of there being no properly designed model including the atmospheric transmission coefficient in the infrared $P_{\text {atm }}=f(d)$ in the thermal imaging camera microcontroller, the results given by the camera are inappropriate - see Fig. 1. It is very important to use a good model of the atmospheric transmission coefficient $P_{\text {atm }}=f(d)$. The paper has some limitations. Thermal imaging camera models should take into account additional factors affecting on the measurement, such as the spectral response. The dependence of the atmospheric transmission for various types of thermal imaging cameras' matrices cannot be brought into one universal plot. Bearing in mind described limitations, in the paper only comparisons of the plots were made.

The function based on Passman-Larmore measurements was introduced as the initial model. All models have similar characteristics (Fig. 9, which becomes more different with the distance; Fig. 10). The model described in the paper of Więcek (2011) can be much more different from the others if the calibration point is not appropriate. Practical and experimental models give similar values of the atmospheric transmission coefficient $P_{\text {atm }}$. This is due to the fact that the model of the atmospheric transmission coefficient is chosen properly. As a result similar results can be obtained using simple calculations. In Figs. 9 and 10 similar conditions 


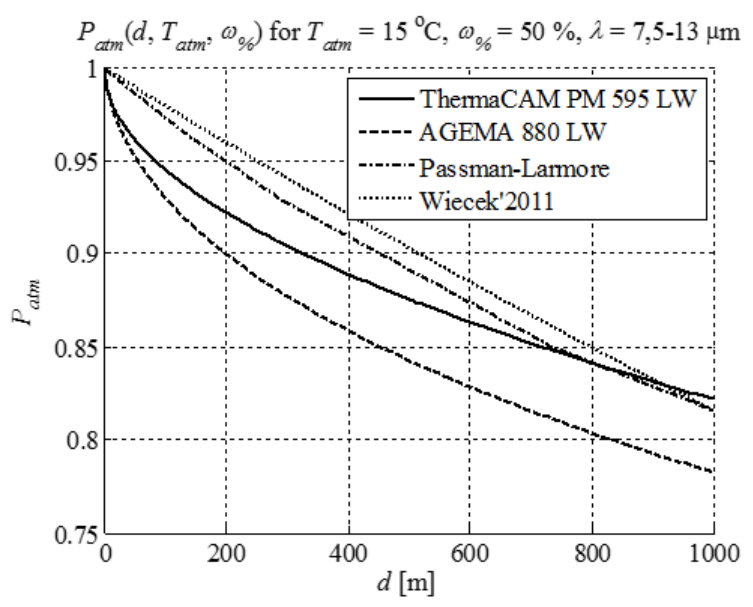

Figure 9. Characteristics of atmospheric transmission coefficient $P_{\text {atm }}=f(d)$ for a few models described in this paper for a distance up to $1000 \mathrm{~m}$.

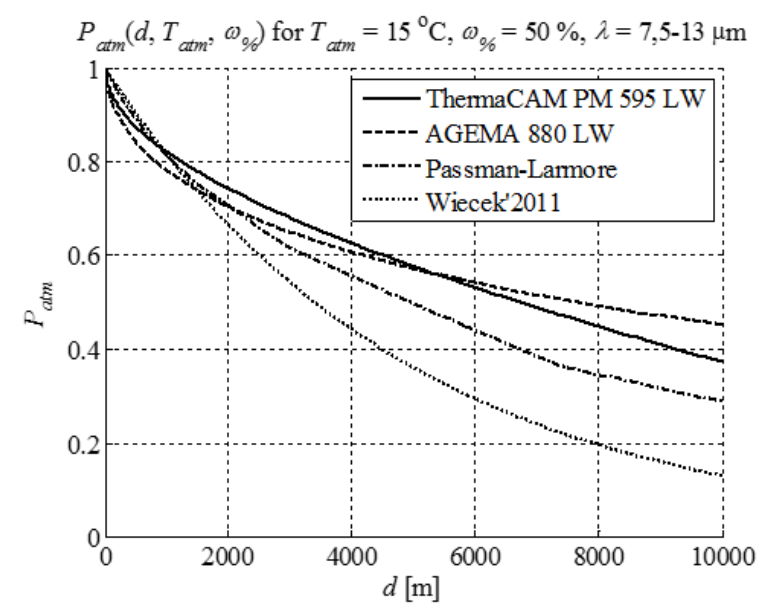

Figure 10. Characteristics of atmospheric transmission coefficient $P_{\mathrm{atm}}=f(d)$ for a few models described in this paper for a distance up to $10000 \mathrm{~m}$.

were applied for all the models in typical measurement situations. In different circumstances comparative characteristics can be different. This results from the fact that the model described in the paper of Więcek (2011) can be used in practice only when the calibration point is chosen properly. Figure 10 shows huge disparities in characteristics of the atmospheric transmission coefficient $P_{\text {atm }}=f(d)$. This is particularly noticeable for distances over $1000 \mathrm{~m}$ (Fig. 10). For a distance up to $1000 \mathrm{~m}$ (Fig. 9) all characteristics are similar. All these models are dedicated to a certain type of cameras. The Passman-Larmore model is the most universal, because it is possible to use tables for different wavelength $\lambda$.

It is well known, that all these models are different, but the aim of this paper is to calculate how big the differences are between the characteristics of the atmospheric transmission as a function of the distance.
It should be noted that the properly calculated atmospheric transmission coefficient in the infrared $P_{\text {atm }}=f(d)$ makes it possible to read the right temperature of the object. A correct value of atmospheric transmission coefficient set in the camera microcontroller is of fundamental importance for accuracy of contact-less measurement of the object temperature (Minkina and Dudzik, 2006, 2009). Additional information about the atmospheric transmission coefficient in the infrared can be found in Anderson et al. (1995), DeWitt (1983), Narasimhan and Nayar (2002) and Roth$\operatorname{man}(2005)$.

Edited by: K.-P. Möllmann

Reviewed by: four anonymous referees

\section{References}

Anderson, G. P., Kneizys, F. X., Chetwynd, J. H., Wang, J., Hoke, M. L., Rothman, L. S., Kimball L. M., McClatchey, R. A., Shettle, E. P., Clough, S. A., Gallery, W. O., Abreu, L. W., and Selby, J. E. A.: FASCODE, MODTRAN, LOWTRAN: past, present, future, Proceedings of the 18th Annual Review Conference on Atmospheric Transmission Models, Boston 6-8 June 1995, 101120, edited by: Anderson, G. P., Picard, R. H., Chetwynd, J. H., 1995.

DeWitt, D. P.: Inferring temperature from optical radiation measurements, Proc. of SPIE, Vol. 0446, Thermosense VI (ÙOctober 1983): An Int. Conf. on Thermal Infrared Sensing for Diagnostics and Control, edited by: Burrer, G. J., 226-233, 1983.

Gaussorgues, G.: Infrared Thermography. Springer Science+Business Media, B. V., Dordrecht, 552 pp., ISBN: 978-94-010-4306-9, 1994.

IR-Book: FLIR Training Proceedings, Level II (Infrared Training Center - International, itc-i), 120 pp., 2000.

Minkina, W. and Dudzik, S.: Simulation analysis of uncertainty of infrared camera measurement and processing path, Measurement, Vol. 39, Nr. 8, 758-763, Elsevier Ltd, 2006.

Minkina, W. and Dudzik, S.: Infrared thermography - errors and uncertainties, John Wiley \& Sons Ltd, Chichester, 222 pp., ISBN: 978-0-470-74718-6, 2009.

Minkina, W. and Klecha, D.: Modeling of atmospheric transmission coefficient in infrared for thermovision measurements 14th International Conference on Infrared Sensors \& Systems (IRS2'2015), 19-21 May 2015, 903-907, Nürnberg, materials on CD-R, doi:10.5162/irs2015/1.4, 2015.

Minkina, W., Dudzik, S., and Gryś, S.: Errors of thermographic measurements - exercises, Proceedings of 10th International Conference on Quantitative Infrared Thermography (QIRT'2010) 27-30 July 2010, Québec, Canada, organization: Université Laval, Electrical and Computer Engineering Department, 503-509, ISBN: 978-2-9809199-1-6, 2010.

Narasimhan, S. G. and Nayar, S. K.: Vision and the atmosphere, Int. J. Comput. Vision, 48, 233-254, 2002.

Orlove, G. L.: Practical thermal measurement techniques, Proc. of SPIE, Vol. 371, Thermosense V (October 1982), Thermal Infrared Sensing Diagnostics, edited by: Courville, G. E., Detroit, Michigan, 72-81, 1982. 
Passman, S. and Larmore, L.: Atmospheric Transmission, Rand Paper, Rand Corporation, Santa Monica, 897 pp., 1956.

Pręgowski, P.: Spectral analysis of radiant signals in processes of tele-thermodetection, Proc. of SPIE, Vol. 4360, Thermosense XXIII, An Int. Conf. on Thermal Sensing and Imaging Diagnostic Applications, edited by: Rozlosnik, A. E., Dinwiddie, R. B., 1-12, 2001.

Pręgowski, P. and Świderski, W.: Experimental determination of the transmission of the atmosphere - based on thermographic measurements, Proc. of 50 Eurotherm Seminar, Quantitative Infrared Thermography (QIRT'1996), Stuttgart (RFN), edited by: Balageas, D., Busse, G., Carlomagno, G. M., 363-367, 1996.

Rothman, L. S.: Jacquemart D., Barbe A., Benner D. Ch. and others: The HITRAN 2004 molecular spectroscopic database, J. Quant. Spectrosc. Ra., 96, 139-204, 2005.

Rudowski, G.: Thermovision and its application, Wydawnictwo Komunikacji i Łączności, Warszawa, 212 pp., 1978 (in Polish).

Saunders, P.: Reflection errors in industrial radiation thermometry, Proc. of 7th Int. Symposium on Temperature and Thermal Measurements in Industry and Science (TEMPMEKO'1999 TC 12), edited by: Dubbeldam, J. F., de Groot, M. J., Delft, 631-636, 13 June 1999.
Toolkit IC2: Dig16 Developers Guide 1.01 for Agema 550/570, ThermaCAM PM $5 \times 5$ and the ThermoVision Family, FLIR Systems 2001 - in the daytime: 20 February 2014, available at: http://u88.n24.queensu.ca/exiftool/forum/index.php?action= dlattach;topic $=4898.0 ;$ attach $=1035$ (last access: 15 January 2016), 2001.

Vollmer, M. and Möllmann, K.-P.: Infrared Thermal Imaging Fundamentals, Research and Applications, Wiley-VCH Verlag GmbH \& Co. KGaA, Weinheim, 594 pp., ISBN: 978-3-52740717-0, 2010.

Więcek, B.: Thermovision in infrared - basics and applications, Measurement Automation Monitoring Publishing House, Warszawa, 372 pp., ISBN: 978-83-926319-7-2 (in Polish), 2011. 